\title{
Medical comorbidities in children and adolescents with autism spectrum disorders and attention deficit hyperactivity disorders: a systematic review
}

\author{
Jet B. Muskens ${ }^{1,2} \cdot$ Fleur P. Velders ${ }^{1,3} \cdot$ Wouter G. Staal ${ }^{1,2,4}$
}

Received: 14 October 2016 / Accepted: 20 June 2017 / Published online: 3 July 2017

(C) The Author(s) 2017. This article is an open access publication

\begin{abstract}
Somatic disorders occur more often in adult psychiatric patients than in the general adult population. However, in child and adolescent psychiatry this association is unclear, mainly due to a lack of integration of existing data. To address this issue, we here present a systematic review on medical comorbidity in the two major developmental disorders autism spectrum disorder (ASD) and attention deficit hyperactivity disorder (ADHD) and formulate clinical recommendations. The literature was searched using the PubMed and PsycINFO databases (2000-1 May 2016) with the keywords " [((child and adolescent) AND (Autism OR Attention Deficit Hyperactivity Disorder* OR ADHD)) AND ("Cardiovascular Diseases" [Mesh] OR "Endocrine System Diseases" [Mesh] OR "Immune System Diseases" [Mesh] OR "Neurobehavioral Manifestations" [Mesh] OR "Gastrointestinal Disorders" [Mesh] OR Somatic OR Autoimmune disease OR Nervous system disease OR Infection OR Infectious disease)]. Two raters independently assessed the quality of the eligible studies. The initial search
\end{abstract}

This article is part of the Focused Issue "The role of nutrition in child and adolescent onset mental disorders" of European Child and Adolescent Psychiatry.

Jet B. Muskens

j.muskens@karakter.com

1 Karakter Child and Adolescent Psychiatry University Center Nijmegen, Reinier Postlaan 12, Nijmegen, The Netherlands

2 Department of Psychiatry, Radboud University Medical Center, Nijmegen, The Netherlands

3 Department of Psychiatry, Brain Center Rudolf Magnus, University Medical Center, Utrecht, The Netherlands

4 Department of Cognitive Neuroscience, Donders Institute for Brain, Cognition and Behaviour Radboudumc, Nijmegen, The Netherlands identified 5278 articles. Based on inclusion and exclusion criteria 104 papers were selected and subsequently subjected to a quality control. This quality was assessed according to a standardized and validated set of criteria and yielded 29 studies for inclusion. This thorough literature search provides an overview of relevant articles on medical comorbidity in ADHD and/or ASD, and shows that medical disorders in these children and adolescents appear to be widespread. Those who work with children with ASD and/or ADHD should be well aware of this and actively promote routine medical assessment. Additionally, casecontrol studies and population-based studies are needed to provide reliable prevalence estimates. Future studies should furthermore focus on a broader evaluation of medical disorders in children and adolescents with ADHD and/or ASD to improve treatment algorithm in this vulnerable group.

Keywords Child and adolescent psychiatry $\cdot$ Medical disorders · Comorbidity · Developmental disorders . Autism spectrum disorder - Attention deficit hyperactivity disorder

\section{Introduction}

Medical disorders occur more often in adult psychiatric patients than in the general population [1]. Moreover, somatic symptoms may cause or enhance psychiatric symptoms [2-4]. A comprehensive review of comorbidity of mental and medical disorders in adults was presented by The Robert Wood Johnson Foundation in 2011, which included its the prevalence, origins and models for effective treatment [5]. More than $68 \%$ of adults with a mental disorder had at least one medical condition. Thereby, comorbidity was associated with elevated symptom burden, 
functional impairment, decreased length and quality of life and increased costs. The pathways between psychiatric symptoms and medical disorders are mostly, if known, complex and bidirectional. For example, adults with hypothyroidism are at risk for mood disorders [6, 7], and patients with schizophrenia and bipolar disorder have an increased risk of developing metabolic syndrome, due to their psychiatric disease as well as the use of antipsychotic drugs $[8,9]$. Moreover, adults with mental health problems are more likely to have sedentary lifestyles and poor diets [5]. Different studies showed that patients with schizophrenia, bipolar disorder, or major depression, report less physical activity compared with those without mental disorders, and tend to eat foods that are high in fat and calories while avoiding fruits and vegetables [10,11].

The increased risk for mental health problems has also been found in children with medical disorders. Findings of the Isle of Wight studies of Sir Michael Rutter and colleagues [12] starting in 1964-1965, already reported that $12 \%$ of children with somatic disorders (non-neurological) exhibited mental health problems compared to $7 \%$ of children in the general population [13, 14]. Also, significantly higher rates of mental health problems were reported in children with epilepsy: $29 \%$ in children with uncomplicated epilepsy and $58 \%$ in those with complicated epilepsy (i.e., structural brain abnormalities and seizures).

Several systematic reviews have been published on the association between specific medical disorders and child psychiatric disorders, for instance on the association between epilepsy and psychopathology [15], atopic diseases and mental health [16, 17], inflammation and neuropsychiatry [18], headaches/migraine and psychopathology [19, 20], HIV/AIDS and mental health [21], gastrointestinal dysfunction and ASD [22], immune factors and ASD [23], phenylketonuria and ADHD [24]. Aldinger and colleagues aimed to identify clustering of medical disorders in children with autism. In this study, the prevalence of medical conditions ranged from 10.7 to $77.4 \%$. A cooccurrence of sleeping problems and gastro-intestinal disturbances in children with autism was found. Also, the cooccurrence of gastro-intestinal disturbances, seizures and sleep problems predicted more severe behavioral symptoms in children with ASD [25]. Buie et al. concluded that medical disorders, such as gastro-intestinal problems, occur commonly in individuals with ASD [26]. However, medical conditions may remain undiagnosed in children with ASD due to atypical presentation of symptoms. Nonverbal or minimally verbal ASD individuals cannot verbally express pain or discomfort and instead often demonstrate their level of discomfort through disruptive behaviors, including aggressions and self-injury [26]. Even patients with ASD who acquire verbal communication skills may have difficulty describing subjective experiences or symptoms.
Clinicians should be aware that problem behavior in ASD may be the primary or sole symptom of the underlying medical disorder. Even more so, Schieve and colleagues showed that children with specific developmental delays (autism, ADHD, learning disorder and intellectual disability) were more likely to have certain medical conditions than children without these delays [27]. Based on this finding, Schieve and colleagues state that children with developmental delays require increased pediatric health services and specialist services, both for their core functional deficits as for their health problems [27]. However, these results were based on parents or caregivers report, without clinical confirmation on developmental delays or medical conditions.

Following the data from reviews and clinical studies, Merikangas and colleagues performed a study on comorbidity of mental and physical conditions and functional impairments in 9014 children and adolescents [28]. In particular, a strong association between ADHD and neurologic disorders (seizures and epilepsy) was found. This association between neurologic disorders that affect brain systems and behavioral disorders is in line with other studies examining developmental disorders such as autism, ADHD, and neurobehavioral problems $[29,30]$. It may implicate dysfunction in the underlying network and common genetic and/or environmental risk factors [31-34].

In a previous pilot study we evaluated the outcome of medical screening at referral in children and adolescents with different psychiatric disorders. This screening revealed new somatic findings in 56\% of the subjects [35]. These findings included a broad spectrum of medical concerns, including weight and length problems, high levels of thyroid hormone, dyslipidemia, anemia, vitamin D and vitamin B12 deficiency and dysmorphic anomalies. Some of these results required consultation from other medical specialists, whereas others had direct implications for daily medical practice, such as adjustments in psychopharmacologic treatment and/or participation in prevention programs for overweight.

These findings all contribute to the increasing awareness about the association between somatic and mental symptoms in developmental disorders and may suggest potential mechanisms such as common genetic pathways [28]. Also, the simultaneous assessment of medical and psychiatric disorders could be of major value. It seems important that the interpretation of meaningful somatic findings is done by clinicians who are able to relate these findings to differential diagnostic considerations for both medical and psychiatric interventions.

Most of the available literature on medical disorders in child and adolescent psychiatric disorders relates to ASD and ADHD, but there is a lack of integration of existing data, hampering the interpretation of findings. Therefore, 
this systematic review focuses on the association of medical disorders with autism and/or ADHD in children and adolescents and provides recommendations for future studies. Our hypothesis is that children with ADHD and ASD are at increased risk for a broad spectrum of medical disorders.

\section{Methods}

\section{Search criteria}

The literature was searched using the PubMed and PsycINFO databases (January 2016) with the following keywords: [((child and adolescent) AND (Autism OR Attention Deficit Hyperactivity Disorder* OR ADHD)) AND ("Cardiovascular Diseases" [Mesh] OR "Endocrine System Diseases" [Mesh] OR "Immune System Diseases" [Mesh] OR "Neurobehavioral Manifestations" [Mesh] OR "Gastrointestinal Disorders" [Mesh] OR Somatic OR Autoimmune disease OR Nervous system disease OR Infection OR Infectious disease)]. To be included in the present review, the articles had to be written in English language and published between 2000 and the first of May 2016.

\section{Screening procedure}

First, the papers were screened on title and abstracts, which was conducted independently by two of the authors (JM and FV) in order to assess the eligibility of the studies. Second, this selection of papers was screened based on the full text. The third author (WS) was consulted in case of differences in scoring by the other two authors. The inclusion and exclusion criteria were as follows.

Inclusion criteria:

1. Sample subjects had to fulfill criteria for autism spectrum disorders (ASD) or attention deficit hyperactivity disorders (ADHD) by DSM-IV [36], DSM-IV-R [37], DSM 5 [38] or ICD-10 [39] or scores above a clinical threshold obtained using instruments for the assessment of ADHD or ASD. ASD encompasses autistic disorders, Asperger's disorder and pervasive developmental disorder-not otherwise specified (PDD-NOS) within the DSM classification system, and childhood autism, infantile autism, atypical autism and Asperger's syndrome in the ICD classification system. Considering the diagnosis of ADHD, studies on attention deficit disorder with or without hyperactivity were both included.

2. A medical or somatic disorder diagnosed by a clinician, from National Health Surveys or databases, or parents' report.
3. The age of the study participants was 18 years or younger including population-based studies started during childhood with follow-up $>18$ years.

\section{Exclusion criteria:}

1. Study design: case report, case series, letter to the editor, editorial, or data solely presented by means of a poster presentation.

2. Study focus: intervention studies in which subjects were selected for pharmacological treatment of ADHD, exposure on chemicals, effects of dietary supplementation, perinatal complications and studies including mental retardation and/or syndromes.

Third, the quality of each study was assessed according to a standardized and validated set of criteria based on the protocols of the Cochrane Database of Systematic Reviews [40]. The papers were scored independently on the 6 criteria below by 2 raters (JM and FV), in order to quantify the methodologic aspects and the quality standard of each study. Each study could obtain a maximum of 6 points (1 point per criterion). Papers with a quality assessment score of 5 or higher were considered of high quality and selected for this review. Inter-rater disagreement was primarily solved by discussion or arbitration of a third rater (WS) to enhance uniformity in the scoring procedure. The following six criteria were used:

1. Comparison group(s): the presence of at least $1 \mathrm{com}-$ parison group (control group), preferably a sample of healthy children from the same population or region as the children with medical disorders or ASD/ADHD.

2. Sample selection: a random selection strategy should be used.

3. Design: a case-control design based on quantitative information or population-based cohort studies.

4. Diagnostic validity: DSM criteria, ICD 10 by clinicians (not only by parent, teacher or self- reports).

5. Outcome measures: medical disorder or ASD/ADHD.

6. Statistical analyses: hypothesis testing using appropriate statistical analyses should be performed.

\section{Results}

The initial search yielded in total 5278 papers (1783 and 3495 hits, respectively, of which 55 duplicates). 4665 papers were excluded according to the title and/ or the abstract and 451 were excluded based on the full text. The remaining 104 papers were scored of which 29 papers were considered of high quality (5 or 6 points) and presented in this review. Two of these 29 papers focused 
on both ADHD and ASD, and are therefore listed in both tables (see Fig. 1).

Table 1 presents the papers that studied the association between ASD and medical disorders: 5 papers on immunology, 6 papers on gastroenterology, 1 paper on neurology and 2 papers on other medical disorders (see Table 1). In Table 2, the papers are listed that studied ADHD and medical disorders: 12 papers on immunology, 1 paper on neurology and 4 papers on other medical disorders (see Table 2).

\section{ASD and immunology}

With regard to a possible association between ASD and immunological disorders, most papers studied allergic disease or autoimmune disease. Jyonouchi et al. evaluated whether one could clinically distinguish a subset of children with ASD and immunological disorders from other ASD children based on the frequency of infections [41]. In this sample, no significant differences were found considering the prevalence of atopy, asthma, food allergy, primary immunodeficiency between children in the ASD test group and controls (ASD controls, non-ASD controls with food allergy, non-ASD controls with frequent infections and normal controls).

Chen et al. concluded, however, that the presence of any atopic disease in early childhood increased the risk of developing ASD (hazard ratio: (HR) 3.40) in later life [42]. Greater numbers of atopic comorbidities (4 comorbidities HR: 4.29) were significantly related to a greater risk of developing ADHD and ASD.

Gentile et al. found similar rates of contact with Herpes Simplex Virus 1 and Herpes Simplex Virus 2 between children with ASD and healthy controls [43].

The study of Puig-Alcatraz et al. found that the increase in homocysteine concentration, suggestive for disorders of the immune system, was significantly correlated with the severity of the deficit in communication skills in children with ASD, but was unrelated to deficit in socialization or repetitive/restricted behavior compared to typically developing children [44].

Contrary to the study of Jynouchi et al., Zerbo et al. reported that allergies and autoimmune diseases were diagnosed significantly more often among children with autism than among controls (allergy: 20.6 vs. $17.7 \%$, crude odds ratio $(\mathrm{OR})=1.22,95 \%$ confidence interval (CI) 1.13-1.31; autoimmune disease: 1 vs. $0.76 \%, \mathrm{OR}=1.36,95 \%$ CI $1.01-1.83$ ), and asthma was diagnosed significantly less often (13.7 vs. $15.9 \%$; $\mathrm{OR}=0.83,95 \%$ CI 0.76-0.90) [45]. Furthermore, psoriasis was seen more often in cases than in controls $(0.34$ vs. $0.15 \%$; OR $=2.35,95 \%$ CI $1.36-4.08)$.

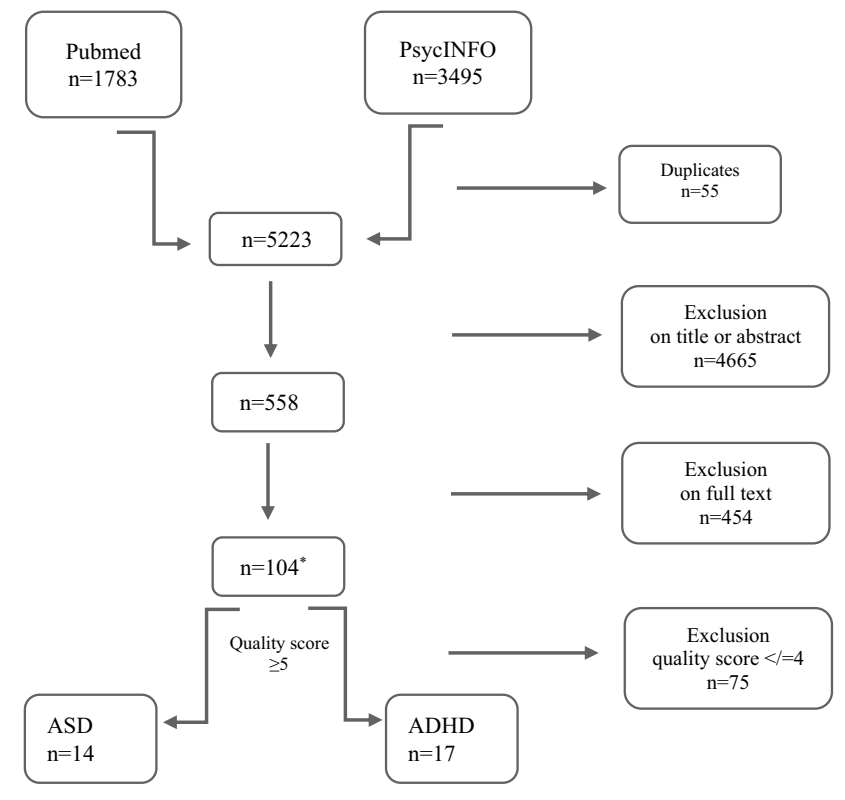

Fig. 1 Flowchart of study search and inclusion in the review. Asterisk two papers are listed under both ASD and ADHD and consequently double represented in the numbers

\section{ASD and gastroenterology}

The study of Valicenti et al. found that children with ASD had a significantly higher rate of gastro-intestinal (GI) symptoms than children with either typical development or other developmental disabilities (history of GI symptoms 70 vs 28 vs $42 \%$, abnormal stool pattern 18 vs 4 vs $2 \%$, food selectivity 60 vs 22 vs $36 \%$ ) [46]. There was no association between a family history of autoimmune disease and GI symptoms in children with ASD.

The longitudinal population-based study of Mouridsen et al. found no evidence that patients with infantile autism (IA) were more likely than controls to have defined gastro-intestinal diseases during a 30.3-year observation period (30.5\% against $30.7 \%$ ) [47]. Only diseases of oral cavity (dental problems) were significantly associated with IA ( 20.3 vs $1.2 \%, p$ value $<0.0001)$.

In the study of Wang et al., parents retrospectively reported significantly more GI problems in children with ASD $(249 / 589 ; 42 \%)$ compared with their unaffected siblings $(20 / 163 ; 12 \%)(p<0.001)$ [43]. The 2 most common gastro-intestinal problems in children with ASD were constipation (20\%) and chronic diarrhea (19\%). Next, individuals with ASD were grouped into 3 autism severity groups (Full Autism, Almost Autism, and Spectrum) based on their Autism Diagnostic Interview-Revised and Autism Diagnostic Observation Scale scores. Increased autism symptom severity was associated with higher odds of gastro-intestinal problems (AOR for trend $=2.63,95 \%$ CI: $1.56-4.45$ ). 
Table 1 Autism spectrum disorders and medical disorders

\begin{tabular}{|c|c|c|c|c|c|c|}
\hline & Authors & Year & $\begin{array}{l}\text { Study size cases/con- } \\
\text { trols }\end{array}$ & Age range (years) & Study design & Medical disorder \\
\hline \multirow[t]{5}{*}{ Immunology } & Jyonouchi et al. & 2008 & $26 / 212$ & $1-18$ & Cross-sectional & $\begin{array}{l}\text { Atopy, asthma, allergy } \\
\text { and immunodeficiency }\end{array}$ \\
\hline & MH Chen et al. & 2014 & $14,812 / 6994$ & $1-14$ & Case-control & $\begin{array}{l}\text { Asthma, atopic dermati- } \\
\text { tis, allergic rhinitis, or } \\
\text { allergic conjunctivitis }\end{array}$ \\
\hline & Gentile et al. & 2014 & $54 / 46$ & $3-9$ & Cross-sectional & $\begin{array}{l}\text { Antibody levels of HSV } 1 \\
\text { and HSV } 2\end{array}$ \\
\hline & Puig-Alcatraz et al. & 2015 & $35 / 34$ & $4-13$ & Cross-sectional & Homocysteine levels \\
\hline & Zerbo et al. & 2015 & $5565 / 27,825$ & $3-26$ & Case-control & $\begin{array}{l}\text { Immune-mediated condi- } \\
\text { tions }\end{array}$ \\
\hline \multirow[t]{6}{*}{ Gastroenterology } & Valicenti et al. & 2006 & $50 / 100$ & $4-12$ & Cross-sectional & $\begin{array}{l}\text { Gastro-intestinal symp- } \\
\text { toms }\end{array}$ \\
\hline & Mouridsen et al. & 2010 & $118 / 336$ & $0-57$ & Case-control & Gastro-intestinal diseases \\
\hline & Wang et al. & 2011 & $589 / 163$ & $1-18$ & Cross-sectional & $\begin{array}{l}\text { Gastro-intestinal prob- } \\
\text { lems }\end{array}$ \\
\hline & Chandler et al. & 2013 & $132 / 163$ & $10-14$ & Cross-sectional & $\begin{array}{l}\text { Gastro-intestinal symp- } \\
\text { toms }\end{array}$ \\
\hline & Mouridsen et al. & 2013 & $89 / 258$ & $3-65$ & Case-control & Gastro-intestinal diseases \\
\hline & Von Gontard et al. & 2015 & $40 / 43$ & $5-17$ & Case-control & $\begin{array}{l}\text { Gastro-intestinal symp- } \\
\text { toms }\end{array}$ \\
\hline Neurology & Mouridsen et al. & 2013 & 4180/general population & $4-31$ & Cross-sectional & Epilepsy \\
\hline \multirow[t]{2}{*}{ Other medical disorders } & Van Tongerloo et al. & 2012 & $49 / 81$ & $8-16$ & Case-control & $\begin{array}{l}\text { Medical comorbidity and } \\
\text { referrals by a general } \\
\text { practitioner }\end{array}$ \\
\hline & Butwicka et al. & 2015 & $9262 / 468,036$ & $1-30$ & Case-control & Hypospadias \\
\hline
\end{tabular}

The increased prevalence of GI symptoms was also found by Chandler et al. In this study, $46.5 \%$ of children with ASD had at least one individual lifetime GI symptom compared with $21.8 \%$ of typically developing children and $29.2 \%$ of the children with special educational needs [48]. No association was found between GI symptoms and intellectual ability, ASD severity, ASD regression or a faddy diet (arbitrary and often unusual likes and dislikes about food).

The study of Mouridsen et al. compared prevalence rates of gastro-intestinal tract diseases (esophagus, stomach, duodenum, gall bladder, biliary tract, pancreas, liver, peritoneum, intestines) in patients with PDD-NOS. In this study, conducted with data from the Danish National Hospital Register, the difference in prevalence of children with autism $(24.7 \%(22 / 88))$ and at least one diagnosis of any disease of the gastro-intestinal tract was not statistically significant (control group 18.2\% (47/258)) $(p=0.22$; odds ratio $=1.5 ; 95 \%$ confidence interval $=0.8-2.6)$. Interestingly, only hernia was significantly associated with autism 11.2 vs $4.7 \%$ ( $p=0.04$; OR $=2.6$; 95\% CI $=1.08-6.2)$. There were no children with inflammatory GI diseases, such as Crohn's disease or ulcerative colitis in the autism group. Hence, in this study people with autism had about the same frequency of gastric, intestinal and hepatic diseases as had controls [49].

The study of Von Gontard et al. showed increased rates of nocturnal enuresis (30.0 vs $0 \%$ ) and daytime urinary incontinence (25.0 vs $4.7 \%$ ) in children with ASD compared to controls. Furthermore, ASD children had more lower urinary tract symptoms (LUTS) especially urgency and postponement, and they needed a longer time to become dry and continent [50].

\section{ASD and neurology}

Mouridsen et al. studied the prevalence of epilepsy among patients with Asperger's syndrome using the Danish National Hospital Register [51]. In a follow-up period of 4-18 years, patients with Asperger's syndrome were more likely to have epilepsy ( $3.9 \%$ in 4180 cases) in comparison with the estimated prevalence of $2 \%$ in the general population.

\section{ASD and other medical disorders}

Van Tongerloo et al. investigated the presence of characteristic complaints of children with ASD presenting to 
Table 2 Attention deficit hyperactivity disorder and medical disorders

\begin{tabular}{|c|c|c|c|c|c|c|}
\hline & Authors & Year & $\begin{array}{l}\text { Study size (cases/con- } \\
\text { trols) }\end{array}$ & Age range (years) & Study design & Medical disorder \\
\hline \multirow[t]{12}{*}{ Immunology } & Gau et al. & 2008 & $86 / 172$ & $4-16$ & Case-control & $\begin{array}{l}\text { Enterovirus } 71 \text { central nervous } \\
\text { system infection }\end{array}$ \\
\hline & Leslie et al. & 2008 & $3650 / 18,114$ & $5-10$ & Case-control & Streptococcal infection \\
\hline & Sanchez et al. & 2009 & $22 / 22$ & $6-14$ & Cross-sectional & Anti-basal ganglia antibodies \\
\hline & Schmitt et al. & 2009 & $1436 / 1436$ & $6-17$ & Cross-sectional & Atopic eczema \\
\hline & Suwan et al. & 2011 & $40 / 40$ & $5-15$ & Cross-sectional & Allergic sensitization and rhinitis \\
\hline & Tsai et al. & 2011 & $60,438 / 116,112$ & $0-17$ & Cross-sectional & Allergic rhinitis \\
\hline & Siyu et al. & 2012 & $48,457 / 178,093$ & $0-17$ & Cross-sectional & Allergic diseases \\
\hline & Chen et al. & 2013 & $4302 / 21,510$ & $5-15$ & Case-control & Diabetes type I and II \\
\hline & Chen et al. & 2013 & $5811 / 23,244$ & $7-23$ & Cross-sectional & Allergic diseases \\
\hline & Tsai et al. & 2013 & $4692 / 18,768$ & $1-18$ & Case-control & Atopic diseases \\
\hline & Bekdas et al. & 2014 & $60 / 30$ & $6-12$ & Cross-sectional & IgG levels of viruses \\
\hline & Chen et al. & 2014 & $14,812 / 6994$ & $1-14$ & Case-control & $\begin{array}{l}\text { Asthma, atopic dermatitis, allergic } \\
\text { rhinitis, or allergic conjunctivitis }\end{array}$ \\
\hline Neurology & $\begin{array}{l}\text { Merikangas } \\
\text { et al. }\end{array}$ & 2015 & 9014 & $8-21$ & Cross-sectional & Physical conditions* \\
\hline \multirow[t]{4}{*}{ Other disorders } & Dillon et al. & 2007 & $79 / 27$ & $5-13$ & Case-control & Adenotonsillectomy \\
\hline & DeMaso et al. & 2014 & $139 / 61$ & $14-17$ & Cross-sectional & D-transposition of the great arteries \\
\hline & Silva et al. & 2014 & $11,902 / 27,304$ & $0-18$ & Cross-sectional & $\begin{array}{l}\text { Hospitalizations and physical } \\
\text { conditions }\end{array}$ \\
\hline & Butwicka et al. & 2015 & $9262 / 468,036$ & $1-30$ & Case-control & Hypospadias \\
\hline
\end{tabular}

* Allergy/immunology, cardiology, endocrine/metabolism, ear/nose/throat, gastroenterology, hematology, nephrology, neurology, oncology, orthopedics, pediatrics, pulmonology/airways, surgery and urology

the general practitioners' practice, in order to enhance early detection and reduce the delay in diagnosing ASD. This study found that children with ASD presented with more traumata (luxations and distortions) (OR 6.57, $p$-value < 0.01) compared to controls. Also, they were more likely referred to the physiotherapist/ergotherapist (OR 12.63, $p$-value < 0.05), speech therapist (OR 7.07, $p$-value $<0.05$ ) and ear-nose-throat specialist (OR 5.54, $p$-value $<0.05)$ [52].

Using data from the Swedish Patient Register, Butwicka et al. studied the prevalence of ASD in men with hypospadias $(n=9626)$ [53]. Hypospadias is associated with autism (OR 3.20; 95\% CI 2.8-3.8) compared to full brothers $(n=4936)$ and the control group $(n=463,100)$.

In Table 2, the papers are listed that studied ADHD and medical disorders: 12 papers on immunology, 1 paper on neurology and 4 papers on other medical disorders (see Table 2).

\section{ADHD and immunology}

This review includes 12 papers on the association between ADHD and immunological disorders. The study of Leslie et al. [48] showed that prior streptococcal infection was associated with obsessive-compulsive disorder, tic disorders, major depressive disorder. Studies have suggested a link between Group A beta-hemolytic streptococcal (GABHS) infections and the onset or worsening pediatric obsessive-compulsive disorder (OCD), Tourette's syndrome (TS) and tic disorder. The prepubertal onset of OCD, TS, or tic disorder with abrupt symptom exacerbation after streptococcal infection has been termed PANDAS (pediatric autoimmune neuropsychiatric disorders associated with streptococcal infection). Furthermore, this study showed that some patients prior to their initial diagnosis of ADHD were more likely to have had a diagnosis of streptococcal infection in the previous year than controls (OR 1.20, 95\% CI 1.06-1.35) [54]. Although ADHD is frequently comorbid with TS, tic disorders, and OCD, comorbidity of ADHD with TS, tic disorders and OCD were excluded. It remains unclear whether this is the result of a nonspecific stress response or secondary to an activation of the immune system.

The study of Sanchez et al. indicated that frequency of anti-basal ganglia antibodies (ABGA) in children with ADHD (non-comorbid with obsessive-compulsive disorder or tics) does not differ from that in matched controls (4 vs 4\%), despite the fact that our ADHD patients had had more recent pharyngeal group A beta-hemolytic 
streptococcus GABHS infections than the controls (51 vs $14 \%, p$-value $=0.007)[55]$.

With regard to atopy, the study of Schmitt et al. found a prevalence of ADHD among patients with atopic eczema (AE) of 5.2 and $3.4 \%$ among controls. Allergic comorbidities (asthma, allergic rhinitis) were not significantly associated with ADHD [56].

The study of Suwan et al. showed significantly increased rates of allergic sensitization ( $p$-value $=0.0048$ ) and allergic rhinitis in children with ADHD ( $p$-value $=0.008$ ) [57]. On the other hand, no differences were observed regarding other allergic diseases, asthma, eczema, allergic conjunctivitis, food allergy and urticarial ( $p$-value $>0.05$ ).

In a population-based study of Tsai et al. allergic rhinitis patients were more likely to have ADHD than the general population $(p$-value < 0.001) [58].

The association between allergy and ADHD was also found by Shyu et al. In their study, allergic children have a higher risk for developing ADHD in comparison with the general population $(p$-value $<0.001)$ [59]. Allergic rhinitis was found to be the most important contributing factor for the development of ADHD compared to the impact of bronchial asthma and atopic dermatitis.

Chen $\mathrm{HJ}$ et al. found a significant association between previously diagnosed diabetes mellitus type 2 and ADHD in children aged $5-15$ years $(\mathrm{OR} 2.75,95 \% \mathrm{CI}=1.82-$ 4.16) [60]. There was no association between diabetes type 1 and ADHD.

Using the National Health Insurance Research Database, Chen $\mathrm{MH}$ et al. showed that patients with dual diagnoses of ADHD and tic disorder had a significantly higher prevalence of allergic diseases including allergic rhinitis, asthma, atopic dermatitis, allergic conjunctivitis than the ADHD alone group, the tic alone group, and the control group (allergic rhinitis 43 vs. 28.4 vs. 33.6 vs. $19.7 \%$, $p$-value $<0.001$, asthma (27.5 vs. 17.2 vs. 18.2 vs. $11.9 \%$, $p$-value $<0.001$, atopic dermatitis 10.6 vs. 8.4 vs. 7.0 vs. $5.9 \%, p$-value $<0.001$, allergic conjunctivitis 55.6 vs. 34.7 vs. 43.5 vs. $26.3 \%, p$-value $<0.001)$ [61].

The study of Tsai et al. found a higher rate of allergic disease in children with ADHD compared to controls, particularly allergic rhinitis (OR $1.8095 \%$ CI 1.69-1.93), and allergic conjunctivitis (OR 1.69; 95\% CI 1.58-1.81 [62]. Children with atopic dermatitis (OR 1.80; 95\% CI 1.582.05 ) and asthma (OR 1.48; 95\% CI 1.24-1.78) were also at higher risk of ADHD. The risk of ADHD increased with numbers of allergic disease and age.

The study of Bekdas et al. presented that patients with ADHD displayed significantly higher positivity for measles IgG (80 vs. $60 \%, p$-value $=0.044$ ) [63]. When patients with ADHD were classified according to their pubertal status, adolescents with ADHD displayed higher positivity for mumps.
Chen $\mathrm{MH}$ et al. found that the presence of any atopic disease in early childhood increased the risk of developing ADHD (HR: 1.97) in later life [42]. Greater numbers of atopic comorbidities (4 comorbidities HR: 2.53 ) were significantly related to a greater risk of developing ADHD.

\section{ADHD and neurology}

Using data from the Neurodevelopmental Genomics Cohort Study, Merikangas et al. showed that children with central nervous system conditions (seizures and epilepsy) were significantly more likely to have ADHD (OR 1.30, $p$-value < 0.001) [28]. There was no significant association between ADHD and gastroenterological, immunological, autoimmune, cardiology, hematology, nephrology, endocrine disorders.

\section{ADHD and other medical disorders}

The study of DeMaso et al. found that adolescents with d-transposition of the great arteries showed increased rates of attention deficit/hyperactivity disorder compared to healthy controls (19 vs. 7\%, $p$-value $=0.03$ ) [64]. In the study of Dillon et al. $27.8 \%$ of the children that underwent adenotonsillectomy had ADHD, whereas only $7.4 \%$ of the control group had ADHD [65]. Among the 22 children diagnosed with ADHD before surgery, 50\% no longer met diagnostic criteria after adenotonsillectomy.

The population-based study of Silva et al. showed that children under 4 years with ADHD were 70\% more likely to be admitted to a hospital compared with controls [66]. Admissions for head injuries, burns, poisons, all other injuries, diseases of the tonsils and adenoids, asthma and early infections were all more common in children with ADHD.

Next to ASD, Butwicka et al. also studied the prevalence of ADHD in men with hypospadias, and found an increased risk of ADHD in men with hypospadias (OR 1.50; 95\% CI 1.3-1.9) [53].

\section{Discussion}

The main finding of this systematic review is that medical disorders in children with ASD and ADHD appear to be widespread, e.g., can manifest across different medical areas, such as immunology, neurology and gastroenterology. Although it was not possible to extract prevalence data for the medical disorders, a reasonable number of studies could be included in this review, which supports the notion that children and adolescents with developmental disorders such as ADHD and ASD often suffer from medical disorders that needs to be investigated and addressed [67]. Likewise, children with medical disorders are at increased 
risk for developmental disorders, which are unfortunately not often recognized $[52,68]$. Nevertheless, it is clear that these children require multidisciplinary medical services, including psychiatric help [28].

Increased awareness about the prevalence and types of comorbidity of medical disorders in developmental disorders is important for several reasons. It is first of all relevant for treatment and care for patients and their parents. Also, it may provide important information for fundamental research and could help to create a better understanding of the disease etiology of ASD and ADHD. Furthermore, insight in specific patterns of comorbidity may have important implications for the development of effective interventions for these disorders [5].

However, most of the studies that were identified by our initial search did not reach the required level of quality to come to more profound interpretations, because they were hampered by limitations in study design, in limited case-control matching and/or relied on parent, teacher or self-report of symptoms rather than systematic diagnostic assessments by experts.

First, most studies provide cross-sectional data thus limiting assessment of temporality and inference of causal pathways for the various conditions studied. Second, most studies examine the impact of a single medical comorbid condition, and studies that looked at a broad range of comorbid medical conditions are scarce. Third, the included studies sometimes show inconsistent results.

There are also limitations related to the design of this systematic review. First of all, given the amount of research in child psychiatry, it has been decided to limit the current systematic review to the two main developmental disorders: ASD and ADHD. Consequently, other psychiatric disorders, such as Gilles de la Tourette syndrome or tic disorders were not included in this review. As for sleeping disorder, it was decided to exclude these from the review since sleeping disorders are frequently not viewed as specific medical disorder, but rather as part of a symptom complex of several neuropsychiatric disorders. For a recent review on sleeping disorders in children with neurodevelopmental disorders, see the study by Blackmer and colleagues [69].

Second, strict criteria for methodologic quality of the studies were used for the inclusion and consequently only 29 studies were selected, out of more than 4000 studies that were identified in our initial search. Third, we excluded studies that were not published in English, which might have led to the exclusion of potentially relevant studies.

Bearing these limitations in mind, several strong aspects about this systematic review allow us to conclude that a valuable overview of data is provided. First, the methodologic quality and strength of evidence of the various studies has been assessed in a systematic manner by using a standardized set of criteria. This helps to appreciate individual studies in a correct manner. Second, two raters independently assessed the quality of the studies, selected from two databases, with a standardized set of criteria. An additional rater was consulted in case of a difference in scoring by the other two raters. Third, by using a predefined search strategy, the potential for bias was reduced.

In conclusion, medical comorbidity in children and adolescents with ASD and ADHD appears to occur in numerous medical areas [27, 70]. This should lead to a critical view on current health care systems, which are often marked by clear divisions between medical disciplines. The data of this review clearly point to a multidisciplinary and integrated approach for children and adolescents with ASD and ADHD. Moreover, collaborative care models should be recommended including both a psychiatric and medical approach; that is treatment models including screening for ADHD and ASD in primary care settings, and screening for common medical conditions in child and adolescent psychiatry. Thereby, clinicians should be aware that problem behavior in developmental disorders may be the only symptom of the underlying somatic disorder. Furthermore, prevention programs are needed to address common risk factors for comorbid conditions, such as obesity, underweight, vitamin deficiency, hypo or hyperthyroidism and dyslipidemia. Identifying and treating somatic and psychiatric comorbidities will improve behavior and overall improve quality of life for both patient and family.

Also, developmental disorders such as autism can be a feature of several underlying genetic syndromes, many of which also entail somatic symptoms. As such, a careful analysis of the combination of ASD and somatic disorders requires an extensive diagnostic scheme to detect such genetic syndromes to consider referral to a clinical geneticist. For a review on this specific topic, see the study by Cohen and colleagues [71].

With respect to research in ASD and ADHD, future studies should not only focus on psychiatric symptoms, but provide a broader evaluation of medical disorders, preferably with longitudinal studies. Likewise, it would also be worth to study a specific group of medical disorders and comorbid ADHD and/or ASD. This may ultimately help to provide a more personalized treatment approach and broaden our insight in etiological aspects of ASD and ADHD.

\section{Compliance with ethical standards}

Conflict of interest On behalf of all authors, the corresponding author states that there is no conflict of interest. 
Open Access This article is distributed under the terms of the Creative Commons Attribution 4.0 International License (http://creativecommons.org/licenses/by/4.0/), which permits unrestricted use, distribution, and reproduction in any medium, provided you give appropriate credit to the original author(s) and the source, provide a link to the Creative Commons license, and indicate if changes were made.

\section{References}

1. Ferguson B, Dudleston K (1986) Detection of physical disorder in newly admitted psychiatric patients. Acta Psychiatr Scand 74(5):485-489

2. Hall RC, Popkin MK, Devaul RA, Faillace LA, Stickney SK (1978) Physical illness presenting as psychiatric disease. Arch Gen Psychiatry 35(11):1315-1320

3. Krummel S, Kathol RG (1987) What you should know about physical evaluations in psychiatric patients. Results of a survey. Gen Hosp Psychiatry 9(4):275-279

4. Sternberg DE (1986) Testing for physical illness in psychiatric patients. J Clin Psychiatry 47(1 Suppl):3-9

5. Druss BG, Walker ER (2011) Mental disorders and medical comorbidity. Synth Project Res Synth Rep 21:1-26

6. Jackson IM (1998) The thyroid axis and depression. Thyroid Off J Am Thyroid Assoc 8(10):951-956. doi:10.1089/ thy.1998.8.951

7. Surks MI, Ortiz E, Daniels GH, Sawin CT, Col NF, Cobin RH, Franklyn JA, Hershman JM, Burman KD, Denke MA, Gorman C, Cooper RS, Weissman NJ (2004) Subclinical thyroid disease: scientific review and guidelines for diagnosis and management. JAMA 291(2):228-238. doi:10.1001/jama.291.2.228

8. Gentile S (2006) Long-term treatment with atypical antipsychotics and the risk of weight gain: a literature analysis. Drug Saf 29(4):303-319

9. Muench J, Hamer AM (2010) Adverse effects of antipsychotic medications. Am Fam Phys 81(5):617-622

10. Daumit GL, Goldberg RW, Anthony C, Dickerson F, Brown CH, Kreyenbuhl J, Wohlheiter K, Dixon LB (2005) Physical activity patterns in adults with severe mental illness. J Nerv Ment Dis 193(10):641-646

11. Compton MT, Daumit GL, Druss BG (2006) Cigarette smoking and overweight/obesity among individuals with serious mental illnesses: a preventive perspective. Harv Rev Psychiatry 14(4):212-222. doi:10.1080/10673220600889256

12. Rutter M, Tizard J, Yule W, Graham P, Whitmore K (1976) Research report: Isle of Wight Studies, 1964-1974. Psychol Med 6(2):313-332

13. Jones JE, Watson R, Sheth R, Caplan R, Koehn M, Seidenberg M, Hermann B (2007) Psychiatric comorbidity in children with new onset epilepsy. Dev Med Child Neurol 49(7):493497. doi:10.1111/j.1469-8749.2007.00493.x

14. Rutter MG, Yule W (1970) A neuropsychiatric study in childhood. Clinics in developmental medicine nos. 35/36. William Heinemann Medical Books, SIMP, London

15. Rodenburg R, Stams GJ, Meijer AM, Aldenkamp AP, Dekovic M (2005) Psychopathology in children with epilepsy: a meta-analysis. J Pediatr Psychol 30(6):453-468. doi:10.1093/jpepsy/jsi071

16. Yaghmaie P, Koudelka CW, Simpson EL (2013) Mental health comorbidity in patients with atopic dermatitis. J Allergy Clin Immunol 131(2):428-433. doi:10.1016/j.jaci.2012.10.041

17. McQuaid EL, Kopel SJ, Nassau JH (2001) Behavioral adjustment in children with asthma: a meta-analysis. JDBP 22(6):430-439
18. Mitchell RH, Goldstein BI (2014) Inflammation in children and adolescents with neuropsychiatric disorders: a systematic review. J Am Acad Child Adolesc Psychiatry 53(3):274-296

19. Bruijn J, Locher H, Passchier J, Dijkstra N, Arts W-F (2010) Psychopathology in children and adolescents with migraine in clinical studies: a systematic review. Pediatrics 126(2):323-332

20. Genizi J, Gordon S, Kerem NC, Srugo I, Shahar E, Ravid S (2013) Primary headaches, attention deficit disorder and learning disabilities in children and adolescents. J Headache Pain 14:54. doi:10.1186/1129-2377-14-54

21. Scharko AM (2006) DSM psychiatric disorders in the context of pediatric HIV/AIDS. AIDS Care 18(5):441-445. doi:10.1080/09540120500213487

22. Vissoker RE, Latzer Y, Gal E (2015) Eating and feeding problems and gastrointestinal dysfunction in Autism Spectrum Disorders. Res Autism Spectr Disord 12:10-21

23. Stigler KA, Sweeten TL, Posey DJ, McDougle CJ (2009) Autism and immune factors: a comprehensive review. Res Autism Spectr Disord 3(4):840-860

24. Antshel KM (2010) ADHD, learning, and academic performance in phenylketonuria. Mol Genet Metab 99(Suppl 1):S52S58. doi:10.1016/j.ymgme.2009.09.013

25. Aldinger KA, Lane CJ, Veenstra-VanderWeele J, Levitt P (2015) Patterns of risk for multiple co-occurring medical conditions replicate across distinct cohorts of children with Autism Spectrum Disorder. Autism Res 8(6):771-781

26. Buie T, Campbell DB, Fuchs GJ 3rd, Furuta GT, Levy J, Vandewater J, Whitaker AH, Atkins D, Bauman ML, Beaudet AL, Carr EG, Gershon MD, Hyman SL, Jirapinyo P, Jyonouchi H, Kooros K, Kushak R, Levitt P, Levy SE, Lewis JD, Murray KF, Natowicz MR, Sabra A, Wershil BK, Weston SC, Zeltzer L, Winter H (2010) Evaluation, diagnosis, and treatment of gastrointestinal disorders in individuals with ASDs: a consensus report. Pediatrics 125(Suppl 1):S1-S18. doi:10.1542/ peds.2009-1878C

27. Schieve LA, Gonzalez V, Boulet SL, Visser SN, Rice CE, Van Naarden BK, Boyle CA (2012) Concurrent medical conditions and health care use and needs among children with learning and behavioral developmental disabilities, National Health Interview Survey, 2006-2010. Res Dev Disabil 33(2):467-476. doi:10.1016/j.ridd.2011.10.008

28. Merikangas KR, Calkins ME, Burstein M, He JP, Chiavacci R, Lateef T, Ruparel K, Gur RC, Lehner T, Hakonarson H, Gur RE (2015) Comorbidity of physical and mental disorders in the neurodevelopmental genomics cohort study. Pediatrics 135(4):e927e938. doi:10.1542/peds.2014-1444

29. Konrad K, Eickhoff SB (2010) Is the ADHD brain wired differently? A review on structural and functional connectivity in attention deficit hyperactivity disorder. Hum Brain Map 31(6):904-916. doi:10.1002/hbm.21058

30. Reilly C, Atkinson P, Das KB, Chin RF, Aylett SE, Burch V, Gillberg C, Scott RC, Neville BG (2014) Neurobehavioral comorbidities in children with active epilepsy: a populationbased study. Pediatrics 133(6):e1586-e1593. doi:10.1542/ peds.2013-3787

31. Talkowski ME, Rosenfeld JA, Blumenthal I, Pillalamarri V, Chiang C, Heilbut A, Ernst C, Hanscom C, Rossin E, Lindgren AM, Pereira S, Ruderfer D, Kirby A, Ripke S, Harris DJ, Lee JH, Ha K, Kim HG, Solomon BD, Gropman AL, Lucente D, Sims K, Ohsumi TK, Borowsky ML, Loranger S, Quade B, Lage K, Miles J, Wu BL, Shen Y, Neale B, Shaffer LG, Daly MJ, Morton CC, Gusella JF (2012) Sequencing chromosomal abnormalities reveals neurodevelopmental loci that confer risk across diagnostic boundaries. Cell 149(3):525-537. doi:10.1016/j. cell.2012.03.028 
32. Mick E, Biederman J, Prince J, Fischer MJ, Faraone SV (2002) Impact of low birth weight on attention-deficit hyperactivity disorder. JDBP 23(1):16-22

33. Indredavik MS, Vik T, Evensen KA, Skranes J, Taraldsen G, Brubakk AM (2010) Perinatal risk and psychiatric outcome in adolescents born preterm with very low birth weight or term small for gestational age. JDBP 31(4):286-294. doi:10.1097/ DBP.0b013e3181d7b1d3

34. Cross-Disorder Group of the Psychiatric Genomics Consortium (2013) Identification of risk loci with shared effects on five major psychiatric disorders: a genome-wide analysis. Lancet 381(9875):1371-1379. doi:10.1016/s0140-6736(12)62129-1

35. Muskens JB, Vermeulen K, van Deurzen PA, Tomesen EM, van der Gaag RJ, Buitelaar JK, Staal WG (2015) Somatic screening in child and adolescent psychiatry: a descriptive pilot study. Tijdschrift voor psychiatrie 57(10):710-718

36. Diagnostic and Statistical Manual of Mental Disorders (1994) 4th edition, Text Revision (DSM-IV-TR). American Psychiatric Association, Washington, DC

37. Diagnostic and Statistical Manual of Mental Disorders (2000) 4th rev. edition, Text Revision (DSM-IV-TR). American Psychiatric Association, Washington, DC

38. Diagnostic and Statistical Manual of Mental Disorders (5th ed.) (2013) American Psychiatric Association, Washington, DC

39. International Statistical Classification of Disease and Related Health Problems, 10th revision (ICD-10) (1992). World Health Organisation, Geneva

40. Higgins JPTGS (2011) Cochrane handbook for systematic reviews of interventions version 5.1.0 [updated March 2011]. The Cochrane Collaboration

41. Jyonouchi H, Geng L, Cushing-Ruby A, Quraishi H (2008) Impact of innate immunity in a subset of children with autism spectrum disorders: a case control study. J Neuroinflamm 5:52. doi:10.1186/1742-2094-5-52

42. Chen MH, Su TP, Chen YS, Hsu JW, Huang KL, Chang WH, Chen TJ, Pan TL, Bai YM (2014) Is atopy in early childhood a risk factor for ADHD and ASD? A longitudinal study. J Psychosom Res 77(4):316-321. doi:10.1016/j.jpsychores.2014.06.006

43. Gentile I, Zappulo E, Bonavolta R, Maresca R, Riccio MP, Buonomo AR, Portella G, Vallefuoco L, Settimi A, Pascotto A, Borgia G, Bravaccio C (2014) Prevalence of herpes simplex virus 1 and 2 antibodies in patients with autism spectrum disorders. In vivo (Athens, Greece) 28(4):667-671

44. Puig-Alcaraz C, Fuentes-Albero M, Calderon J, Garrote D, Cauli O (2015) Increased homocysteine levels correlate with the communication deficit in children with autism spectrum disorder. Psychiatry Res 229(3):1031-1037. doi:10.1016/j. psychres.2015.05.021

45. Zerbo O, Leong A, Barcellos L, Bernal P, Fireman B, Croen LA (2015) Immune mediated conditions in autism spectrum disorders. Brain Behav Immun 46:232-236. doi:10.1016/j. bbi.2015.02.001

46. Valicenti-McDermott M, McVicar K, Rapin I, Wershil BK, Cohen H, Shinnar S (2006) Frequency of gastrointestinal symptoms in children with autistic spectrum disorders and association with family history of autoimmune disease. JDBP 27(2 Suppl):S128-S136

47. Mouridsen S, Rich B, Isager T (2010) A longitudinal study of gastrointestinal diseases in individuals diagnosed with infantile autism as children. Child Care Health Dev 36(3):437-443

48. Chandler S, Carcani-Rathwell I, Charman T, Pickles A, Loucas T, Meldrum D, Simonoff E, Sullivan P, Baird G (2013) Parentreported gastro-intestinal symptoms in children with autism spectrum disorders. J Autism Dev Disord 43(12):2737-2747

49. Mouridsen SE, Isager T, Rich B (2013) Diseases of the gastrointestinal tract in individuals diagnosed as children with atypical autism: a Danish register study based on hospital diagnoses. Autism 17(1):55-63

50. von Gontard A, Pirrung M, Niemczyk J, Equit M (2015) Incontinence in children with autism spectrum disorder. J Pediatr Urol 11(5):264.e261-267. doi:10.1016/j.jpurol.2015.04.015

51. Mouridsen SE, Rich B, Isager T (2013) Epilepsy in individuals with a history of Asperger's syndrome: a Danish nationwide register-based cohort study. J Autism Dev Disord 43(6):1308-1313

52. van Tongerloo MA, Bor HH, Lagro-Janssen AL (2012) Detecting autism spectrum disorders in the general practitioner's practice. J Autism Dev Disord 42(8):1531-1538

53. Butwicka A, Lichtenstein P, Landen M, Nordenvall AS, Nordenstrom A, Nordenskjold A, Frisen L (2015) Hypospadias and increased risk for neurodevelopmental disorders. J Child Psychol Psychiatry 56(2):155-161. doi:10.1111/jcpp. 12290

54. Leslie DL, Kozma L, Martin A, Landeros A, Katsovich L, King RA, Leckman JF (2008) Neuropsychiatric disorders associated with streptococcal infection: a case-control study among privately insured children. J Am Acad Child Adolesc Psychiatry 47(10):1166-1172. doi:10.1097/CHI.0b013e3181825a3d

55. Sanchez-Carpintero R, Albesa SA, Crespo N, Villoslada P, Narbona J (2009) A preliminary study of the frequency of anti-basal ganglia antibodies and streptococcal infection in attention deficit/ hyperactivity disorder. J Neurol 256(7):1103-1108. doi:10.1007/ s00415-009-5076-8

56. Schmitt J, Romanos M, Schmitt NM, Meurer M, Kirch W (2009) Atopic eczema and attention-deficit/hyperactivity disorder in a population-based sample of children and adolescents. JAMA 301(7):724-726. doi:10.1001/jama.2009.136

57. Suwan P, Akaramethathip D, Noipayak P (2011) Association between allergic sensitization and attention deficit hyperactivity disorder (ADHD). Asian Pac J Allergy Immunol/Launch Allergy Immunol Soc Thailand 29(1):57-65

58. Tsai MC, Lin HK, Lin CH, Fu LS (2011) Prevalence of attention deficit/hyperactivity disorder in pediatric allergic rhinitis: a nationwide population-based study. Allergy Asthma Proc Off J Region State Allergy Soc 32(6):41-46. doi:10.2500/ aap.2011.32.3489

59. Shyu CS, Lin HK, Lin CH, Fu LS (2012) Prevalence of attention-deficit/hyperactivity disorder in patients with pediatric allergic disorders: a nationwide, population-based study. Journal of microbiology, immunology, and infection. Wei mian yu gan ran za zhi 45(3):237-242. doi:10.1016/j.jmii.2011.11.008

60. Chen HJ, Lee YJ, Yeh GC, Lin HC (2013) Association of attention-deficit/hyperactivity disorder with diabetes: a populationbased study. Pediatr Res 73(4 Pt 1):492-496. doi:10.1038/ pr.2013.5

61. Chen MH, Su TP, Chen YS, Hsu JW, Huang KL, Chang WH, Bai YM (2013) Attention deficit hyperactivity disorder, tic disorder, and allergy: is there a link? A nationwide population-based study. J Child Psychol Psychiatry 54(5):545-551. doi:10.1111/ jcpp. 12018

62. Tsai JD, Chang SN, Mou CH, Sung FC, Lue KH (2013) Association between atopic diseases and attention-deficit/hyperactivity disorder in childhood: a population-based case-control study. Ann Epidemiol 23(4):185-188. doi:10.1016/j. annepidem.2012.12.015

63. Bekdas M, Tufan AE, Hakyemez IN, Tas T, Altunhan H, Demircioglu F, Kismet E (2014) Subclinical immune reactions to viral infections may correlate with child and adolescent diagnosis of attention-deficit/hyperactivity disorder: a preliminary study from Turkey. Afr Health Sci 14(2):439-445. doi:10.4314/ahs.v14i2.21

64. DeMaso DR, Labella M, Taylor GA, Forbes PW, Stopp C, Bellinger DC, Rivkin MJ, Wypij D, Newburger JW (2014) Psychiatric disorders and function in adolescents with d-transposition 
of the great arteries. J Pediatr 165(4):760-766. doi:10.1016/j. jpeds.2014.06.029

65. Dillon JE, Blunden S, Ruzicka DL, Guire KE, Champine D, Weatherly RA, Hodges EK, Giordani BJ, Chervin RD (2007) DSM-IV diagnoses and obstructive sleep apnea in children before and 1 year after adenotonsillectomy. J Am Acad Child Adolesc Psychiatry 46(11):1425-1436

66. Silva D, Colvin L, Hagemann E, Stanley F, Bower C (2014) Children diagnosed with attention deficit disorder and their hospitalisations: population data linkage study. Eur Child Adolesc Psychiatry 23(11):1043-1050

67. Gillberg C, Billstedt E (2000) Autism and Asperger syndrome: coexistence with other clinical disorders. Acta Psychiatr Scand 102(5):321-330

68. Petersen MC, Kube DA, Whitaker TM, Graff JC, Palmer FB (2009) Prevalence of developmental and behavioral disorders in a pediatric hospital. Pediatrics 123(3):e490-e495. doi:10.1542/ peds.2008-2750

69. Blackmer AB, Feinstein JA (2016) Management of sleep disorders in children with neurodevelopmental disorders: a review. Pharmacotherapy 36(1):84-98. doi:10.1002/phar.1686

70. Cadman D, Boyle M, Szatmari P, Offord DR (1987) Chronic illness, disability, and mental and social well-being: findings of the Ontario Child Health Study. Pediatrics 79(5):805-813

71. Cohen D, Pichard N, Tordjman S, Baumann C, Burglen L, Excoffier E, Lazar G, Mazet P, Pinquier C, Verloes A, Heron D (2005) Specific genetic disorders and autism: clinical contribution towards their identification. J Autism Dev Disord 35(1):103-116 